\title{
What is Anticipation and What is Not? Comment on Nauts, Metzmacher, Verwijmeren, Rommeswinkel, and Karremans (2011)
}

\author{
Mihai Nadin
}

Published online: 21 March 2012

(C) Springer Science+Business Media, LLC 2012

There are contributions to science that catch the public's attention for the wrong reason(s). The article by Nauts, Metzmacher, Verwijmeren, Rommeswinkel, and Karremans (2011), entitled "The Mere Anticipation of an Interaction with a Woman Can Impair Men's Cognitive Performance," is an example. It was interpreted as: The man's mere thought of having sex with a woman affects his cognitive performance. Some believe that this is trivial. Others wonder why the opposite sex would do it without any impairment.

Nauts et al. provide a good overview of what is so far known. Karremans, Verwijmeren, Pronk, and Reitsma (2009) state: "Interacting with women can impair men's cognitive functioning." Precise, to the point. Ronay and von Hippel (2010) showed that the presence of an attractive woman elevated testosterone and physical risk taking in young men. Again: precise, to the point.

Nauts et al. add a concept that they either don't understand or misrepresent: anticipation. Since Rosen (1985) and Nadin (1987, 2003), anticipation has been described as behavior defined by possible future states as well as by previous states. The expectation of, desire for, and fantasizing about sexual encounters do not qualify as anticipation. Moreover, the distinction between "anticipated interaction" and "pseudo-interactions" is epistemologically vacuous. Anticipation is always expressed in action (Nadin 2010). Instant messaging (as pseudo-interaction) cannot be subject to anticipation, but rather to intention or to planning.

Things get even more confused when "trying to impress a woman" is compared to the effort "not to appear as prejudiced" while "interacting with African-Americans." (By the way, why

\section{Nadin ( $\square)$}

Institute for Research in Anticipatory Systems,

University of Texas at Dallas, AT 10, 800 West Campbell Road,

Richardson, TX 75080-3021, USA

e-mail: nadin@utdallas.edu not use the term Blacks, since the majority of Blacks are not Americans?) The description, "merely anticipating other types of high maintenance interactions might also affect people's cog nitive performance," ignores the autonomic function of anticipation in the living.

Terminological discipline is a minimum to be expected from researchers. Even well-designed experiments cannot compensate for the misuse of concepts. In reality, the article does not have anticipation as a subject, but impression management and its cognitive (and emotional) cost. A study of impression expressed as anticipatory process is yet to be carried out-hopefully, by researchers who know what anticipation is and how it differs from prediction, expectation, forecast, and planning.

\section{References}

Karremans, J. C., Verwijmeren, T., Pronk, T. M., \& Reitsma, M. (2009). Interacting with women can impair men's cognitive functioning. Journal of Experimental Social Psychology, 45, 1041-1044.

Nadin, M. (1987). Mind: Anticipation and chaos. Stuttgart: Belser Verlag. Nadin, M. (2003). Anticipation: The end is where we start from. Baden: L. Muller Verlag.

Nadin, M. (2010). Anticipation and dynamics: Rosen's anticipation in the perspective of time. International Journal of General Systems, 39, 3-33.

Nauts, S., Metzmacher, M., Verwijmeren, T., Rommeswinkel, V., \& Karremans, J. C. (2011). The mere anticipation of an interaction with a woman can impair men's cognitive performance. Archives of Sexual Behavior. doi:10.1007/s10508-011-9860-z.

Ronay, R., \& von Hippel, W. (2010). The presence of an attractive woman elevates testosterone and physical risk taking in young men. Social Psychological and Personality Science, 1, 57-64.

Rosen, R. (1985). Anticipatory systems. Philosophical, mathematical and methodological foundations. New York: Pergamon Press. 